ISSN 2075-5309

www.mdpi.com/journal/buildings/

Article

\title{
Lifting Wing in Constructing Tall Buildings -Aerodynamic Testing
}

Ian Skelton $^{1, *}$, Peter Demian ${ }^{1}$, Jacqui Glass ${ }^{1}$, Dino Bouchlaghem ${ }^{2}$ and Chimay Anumba ${ }^{3}$

1 School of Civil and Building Engineering, Loughborough University, LE11 3TU, UK;

E-Mails: p.demian@1boro.co.uk (P.D.); j.glass@1boro.co.uk (J.G.)

2 School of Architecture, Nottingham Trent University, NG1 4BU, UK;

E-Mail: dino.bouchlaghem@ntu.co.uk

3 Department of Architectural Engineering, Pennsylvania State University, University Park, State College, PA 16801, USA; E-Mail: anumba@engr.psu.edu

* Author to whom correspondence should be addressed; E-Mail: irskelton69@gmail.com; Tel: +44-(0)-790-408-4369.

Received: 23 December 2013; in revised form: 17 February 2014 / Accepted: 13 May 2014 / Published: 28 May 2014

\begin{abstract}
This paper builds on previous research by the authors which determined the global state-of-the-art of constructing tall buildings by surveying the most active specialist tall building professionals around the globe. That research identified the effect of wind on tower cranes as a highly ranked, common critical issue in tall building construction. The research reported here presents a design for a "Lifting Wing," a uniquely designed shroud which potentially allows the lifting of building materials by a tower crane in higher and more unstable wind conditions, thereby reducing delay on the programmed critical path of a tall building. Wind tunnel tests were undertaken to compare the aerodynamic performance of a scale model of a typical "brick-shaped" construction load (replicating a load profile most commonly lifted via a tower crane) against the aerodynamic performance of the scale model of the Lifting Wing in a range of wind conditions. The data indicate that the Lifting Wing improves the aerodynamic performance by a factor of up to $50 \%$.
\end{abstract}

Keywords: aerodynamic; wind tunnel; tower crane; tall building; construction; innovation 


\section{Introduction}

The primary concern in the engineering of tall buildings is the effect of the wind on the building's structure. Each uniquely shaped section of the world's tallest tower (Burj Dubai) prevents the wind from becoming organised and limits lateral movement [1].

The Lifting Wing applies this fundamental engineering concept to the actual build process of a tall building and its life blood, the tower crane.

Previous research undertaken for "Britain's Tall Building Boom: Now Bust?" [2] and "The State of the Art of Building Tall" [3] provided a unique snapshot of the Britain's unprecedented demand for tall buildings in first quarter of 2007 to end of 2008 and the global state-of-the-art of the tall building industry over the first to third quarters of 2008. This research captured the industry's buoyant mood and strong belief in continual growth in demand for tall buildings, especially for those of "iconic" design. It also captured the industry's unexpected thirst for innovation in the build process over tried-and-tested approaches. The four key results were:

- The international construction industry is not keeping pace with the latest, cutting-edge design developments in tall buildings, and that the UK construction industry is not keeping pace with overseas construction industry developments;

- "Inclement weather (winding-off tower cranes)," consistently ranked one of the two highest construction risks, followed by "logistical problems (man and material access via hoist and crane)," "superstructure cycle times/speed of erection" and "façade installation," all directly related to wind and its effect on the tower crane;

- Tall building experts believe "construction programme surety" and "cost certainty" were the two most significant risks of a tall build. The most important attribute of a principal contractor was determined as "innovative build approach and the provision of an experienced tall building team," followed by "history of programme certainty," "logistics management efficiency," reinforcing the industry's thirst for innovation, as well as desire for logistical, programme and therefore cost certainty;

- Eighty percent of tall building experts interviewed would strongly embrace and promote the use of the innovative construction technique that reduces the effect of wind on tower crane material lifts on their tall building project.

The conclusion of that paper's research was that there was strong international desire for an innovative solution to critical construction problems, the most highly ranked of which was wind negatively affecting the build. Paired with the key desire of programme certainty and hence cost certainty, this clearly signposted that an innovative concept was needed to mitigate delays to the tall building programme duration by reducing the effect of wind on the critical path activities of the tower crane. This focused the final stage of the research on the design and testing of an innovative concept named the "Lifting Wing," aimed at directly addressing this industry need.

This paper describes the scientific advancement in applying aerodynamic theory, refined via modelling and testing, to a specific aspect of the building process of a tall building with potentially significant time and commercial benefits. The specific research undertaken in design, modelling and methodologically testing an aerodynamic shroud, was aimed at reducing the wind-induced load on a 
tower crane and the construction material being lifted, thereby allowing lifting in higher wind conditions, reducing the UK average of $40 \%$ down time for a tall building tower crane. This would therefore potentially reduce very costly wind-induced critical path delay to a tall building construction period.

\subsection{Wind and its Effect on Tower Cranes-The Life Blood of the Tall Building}

Tower cranes have come to symbolize the construction industry and perform an indispensable service in moving material components horizontally and vertically to their required positions. They are central to mid- and high-rise building projects [4]. They have become internationally recognised as a highly visible gauge of a city's economic growth. In the UK, if the view of London's skyline from the city to St Paul's Cathedral is unblemished by Wolff, Liebherr and Pontain cranes, then a slump is on the horizon [5]. In the US, the popularity of tower cranes has been slower to develop; however, in 2006, Miami was named "Crane City," as over 300 tower cranes were estimated to be working [6].

It is universally recognised that the tower crane's main weakness is the debilitating affect that high or gusting wind conditions can have on their ability to perform their critical construction role, hence there is a risk of delay to the tall building programme through a drop-or even halt-in the construction productivity rate. This delay can have huge commercial and reputational consequences for the builder if a tall building project is not completed and handed over in accordance with the construction contract dates.

There have been many technical advancements in computerisation, communication and control of tower cranes, the latest of which are integral to new cranes and available as retro-fit kit for older cranes [7], all aimed at improving productivity and safety. However, there have been no advancements aimed at the crane's oldest adversary — wind. The Lifting Wing aims to address this imbalance.

Wind forces exerted on the lattice structure of a tower crane and the construction load suspended from the crane hook directly affect the ability to safely operate and control a crane and its construction material load. The higher the wind speed, the greater the force exerted on the crane and load, and the greater the likelihood of having to shut down crane operations and hence site productivity on programme critical activities drops. The force exerted is wind pressure, caused by air particles travelling at speed and hitting a stationary object - in this case, the crane structure and its bulky suspended load. Wind pressure varies as the square of wind speed. Therefore, if wind speed doubles, the wind pressure increases by a factor of four. A relatively small increase of wind speed can therefore have a significant effect on the safe lifting operations of a tower crane.

Tower cranes are designed to international standards that specify the "in-service" wind speed that a crane must be able to withstand and operate safely. These are typically $14 \mathrm{~m} / \mathrm{s}(31 \mathrm{mph})$ for mobile cranes and $20 \mathrm{~m} / \mathrm{s}$ (45 mph, Beaufort Scale Gale Force 8) for tower cranes [8]. However, the reality of the construction site is that the Tower Crane Operator will decide to take the crane out of service at a wind speed significantly lower that the manufacturer's prescribed "out of service" speed, due to their increased difficulty in safely controlling the crane. This is recommended practice in the UK crane industry [9]. The primary reason for the inability to control the crane is due to the effect of the wind pressure on the construction load being lifted, rather than the crane structure itself. Wind pressure acting on the load suspended at the end of the tower crane's lifting cable results in increasing difficulty for the operator controlling the crane's operations of lift, swing, travel, lowering and landing of loads 
on a congested construction site. This causes a significant safety risk, not only for the crane operator, but for any operatives in the vicinity of the crane and its load. This effect results in the crane ceasing operations at relatively low wind speed with a relatively frequent occurrence, hence critical path programme activities are commonly delayed.

\subsection{The Effect of Wind on Suspended Loads}

Strong winds tend to gust rather than blow consistently. This is amplified in tall building construction site locations which are generally in, or adjacent to, built-up clusters in city centres. The neighbouring buildings tend to break up the relatively smooth flow of wind over open land and cause turbulent or separated flow. This turbulent flow of air across a tower crane and its load can result in an induced rotating (yaw) and swinging motion (drag caused by a gusting wind) on the suspended construction load, pushing it out of balance, increasing the radius from the centre of gravity of the crane and therefore the overturning moment on the crane, potentially making the tower crane unstable. For a relatively light load with a large surface area, such as formwork shutters for concrete frame buildings, steel floor pans for steel frame buildings or cladding panels, this situation will occur significantly below the tower crane's design wind speed.

For example, a wind speed of $14 \mathrm{~m} / \mathrm{s}(30 \mathrm{mph})$ generates a wind load on a $2.5 \mathrm{~m} \times 1.3 \mathrm{~m}(8 \mathrm{ft} \times 4 \mathrm{ft})$ standard formwork shutter of 372 Newtons (N). If the wind speed increases by circa $50 \%$ to $20 \mathrm{~m} / \mathrm{s}$ (45 mph), the wind load rises to $740 \mathrm{~N}$ an almost $100 \%$ increase of load. If this wind blows from behind the crane, the load radius will be significantly increased, potentially overloading the crane. For example, a formwork shutter weighing $750 \mathrm{~kg}$ with an area of $3.25 \mathrm{~m}^{2}$ and suspended on a $27 \mathrm{~m}$ cable will move $1.4 \mathrm{~m}$ from the vertical when subjected to a $14 \mathrm{~m} / \mathrm{s}(30 \mathrm{mph})$ wind. Moving the load radius by this distance on a 35 tonne capacity crane with a $34 \mathrm{~m}$ main boom working at $18 \mathrm{~m}$ radius would reduce the rated capacity from $950 \mathrm{~kg}$ to $640 \mathrm{~kg}$. If this occurs close to the lifting and radius limit of a tower crane, the result could be a catastrophic crane collapse.

This has occurred many times across the world with disastrous effect, the most famous of which is "Big Blue," a giant Lampson Transi-Lift crane that collapsed due to the effect of wind on its load whilst building Miller Park, the Milwaukee Brewers Stadium, USA [10], which was recorded by the Occupational Safety \& Health Administration safety inspector on site the day of the collapse [11]. It had a rated capacity of 1500 tonnes and was lifting a load of 450 tonnes, well inside its maximum capacity. Upon investigation by independent specialist bodies, the concluded primary factor of the collapse was the high wind load acting on the section of roof being lifted and lack of consideration of those loads on the crane's rated capacity [12].

\section{Hypothesis}

Conclusions from the earlier published paper summarised above [3] which signposted a widespread demand for innovation in the area of wind and its negative effect on the construction process, along with research undertaken in aerodynamic theory and site observations of the effect of wind force on a suspended load of a tower crane on many of the authors' construction projects, led to the idea of reducing the effect of this force by sheathing construction materials in an aerodynamic profile during lifting operations. This would reduce the wind force effect on the load, create more stable flight 
characteristics, ultimately reducing the loads imposed on a tower crane and thereby increasing the ability to lift safely in challenging wind conditions.

Various profiles were investigated to achieve the best compromise of two diametrically opposed requirements: that of an aerodynamic shape and the ability to allow large and irregular shaped construction materials to be encapsulated within the aerodynamic profile. A section of an aerofoil (a two-dimensional wing) in a horizontal orientation was ultimately selected, as established aerodynamic research shows that at low approach angles the air flow is able to follow the curve of the upper and lower surfaces of the aerofoil closely, then join smoothly towards the trailing edge, minimising eddies [13]. There remains a relatively high pressure region at the front, but the low pressure at the rear is much closer to atmospheric pressure, resulting in a resistance (coefficient of drag, CDrag) that is around 20 times less than a flat sheet and 10 times less than a cylinder profile [14]. CDrag is a dimensionless quantity that is used to quantify the drag or resistance of the Wing in air. The lower the CDrag, the less aerodynamic drag on the surface of the shape.

Figure 1 is a view from above a section of aerofoil and shows the smooth flow of air from left to right over the streamlined shape, but that flow separation occurs progressively as the aerofoil is turned at an oblique angle to the air flow (yaw angle). The Lifting Wing aerofoil design aims to prevent this "stall" effect by being freely suspended from the tower crane lifting cable, ensuring it is free to rotate and remain "nose to wind," presenting the minimal surface area to the prevailing wind direction, thereby minimising the effect of wind on the tower crane suspended load.

Figure 1. Increasing flow separation as yaw angle increases [14]. (Reprinted with permission from [14]. Copyright 2012 Prentice Hall).

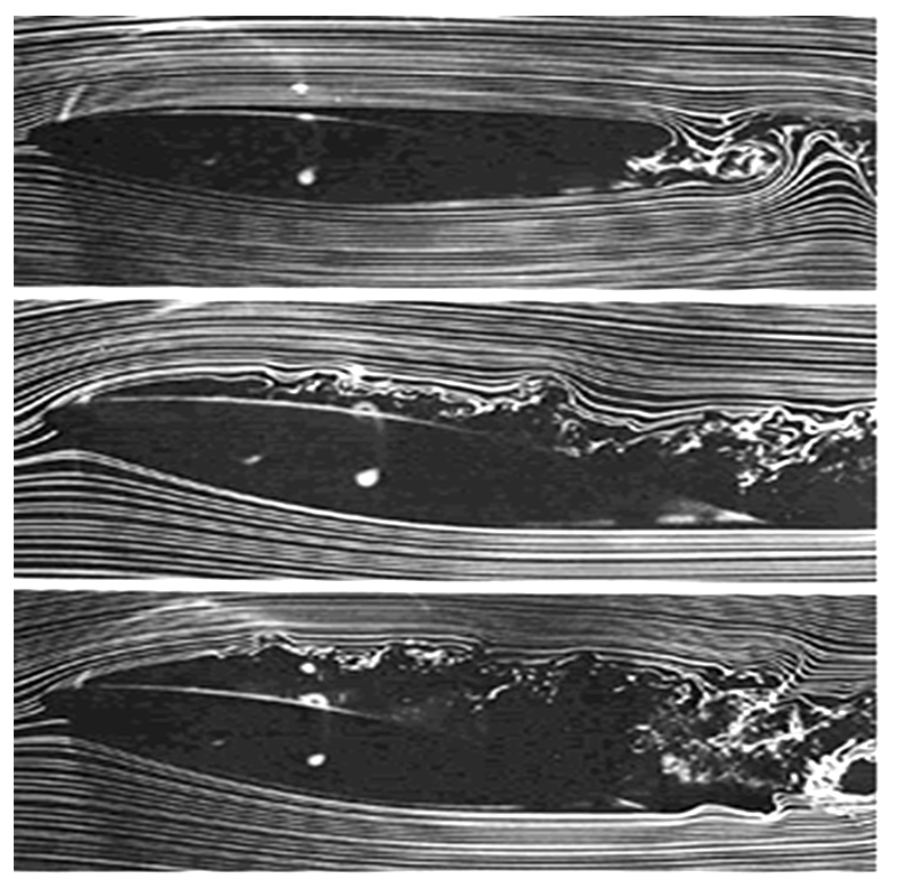

As an aerodynamic ideal, the Lifting Wing design would follow a slim, streamlined aerofoil profile with a sharp trailing edge [15]. However, the practical consideration of ensuring typically large construction loads can be accommodated inside the profile outweighs the desire to reduce the 
drag $(\mathrm{Cd})$ to an absolute minimum level. This results in an aerofoil profile that is wider than the ideal, but still aerodynamically efficient.

\subsection{NACA Foil Design}

The National Advisory Committee for Aeronautics (NACA) conducted extensive research into aerofoils from the 1930s, some of which are still utilised in aircraft manufacturing [16]. They are defined by four-digit wing sections:

- The first digit describes the maximum camber as percentage of the chord (the line between the leading and trailing edges);

- The second digit describes the distance of maximum camber from the aerofoil leading edge in tens of percent of the chord;

- The third and fourth digits describe the maximum width of the aerofoil as percent of the chord.

The XFOIL programme [17] was utilised to review 2D aerofoils between NACA 0012-50 to determine the most suitable profile that when extrapolated into a 3D shape would achieve a balance between aerodynamic efficiency and sufficient width to accommodate an array of typical construction load dimensions.

NACA 0035 (00 indicating that it has no camber, 35 indicates that the aerofoil has a 35\% width to chord length ratio) was ultimately selected as the profile most suitable for the Lifting Wing design, balancing length and width to accommodate the largest, most commonly lifted tall building construction loads. An analysis was undertaken of materials most commonly lifted in the construction of typical concrete and steel-framed tall buildings. This analysis showed that metal floor pans or decking used as permanent formwork for concrete floors in the majority of steel-framed tall buildings, plus timber formwork, bundles of structural steel or concrete planks for concrete framed tall buildings (both commonly $1.2 \mathrm{~m}$ wide and up to $5 \mathrm{~m}$ long) can be inserted within the profile which would have a chord length of $6 \mathrm{~m}$ at full scale. The selected profile would also comfortably accommodate typical individual or loose loads such as mechanical and electrical services components, concrete kibbles and skips, edge protection screens, and palletised or bagged loads such as blocks, sand and cement. At full scale, the selected profile would accommodate these most commonly lifted items, whilst offering a relatively narrow frontal area, smooth flow path around the flanks to minimised flow separation and a sharp trailing edge to minimise drag and side forces otherwise exerted on the load and transferred to the crane.

\subsection{The Lifting Wing}

The full-scale Lifting Wing described by the NACA 0035 aerodynamic profile would be $6 \mathrm{~m}$ long $\times 2.10 \mathrm{~m}$ wide by $2.0 \mathrm{~m}$ high, built of a lightweight, high impact resistant clear plastic skin over a stiff, skeletal frame. It would be open at the top and bottom to allow it to be lowered over the load and for access to the lifting chains. It will be hung with three-point lifting chains attached to the crane hook and lowered by crane over the construction materials to be lifted. The load is then propped/strapped inside the Wing, restraining the load's position relative to the Wing. The Wing fully encapsulates the load, which is directly suspended from the hook of the tower crane. The Wing profile 
then gives the load an aerodynamically efficient, predictable and more controllable profile in high wind speeds. A smaller version would be made to accommodate smaller loads such as palletised and bagged loads, $3 \mathrm{~m}$ long and $1.5 \mathrm{~m}$ high.

Following established aerodynamic theory, the Wing would reduce the key drag load and pitching moment (which would cause the suspended material to swing fore and aft on a crane rope), along with side force and yaw (which would cause lateral oscillation of the lifted material) induced by the wind forces acting on the load being lifted. This is diagrammatically shown in Figure 6. The reduction of the effect of these wind-force-induced loads and a more stable "flight" of the lift should result in safer lifting of construction materials in higher and gustier wind-speed conditions than the current industry standard. The ultimate objective is to reduce the industry-accepted norm of $40 \%$ "down time" for the tower crane over the construction phase of a tall building due to "winding off." This would thereby save time on the critical path of the tall building construction programme and, hence, substantial costs. This theory was then tested by building a scale model of the Lifting Wing for wind tunnel testing.

\section{Aerodynamic Testing}

\subsection{Aim of the Testing Programme}

Tests were conducted at Loughborough University's open circuit wind tunnel, the layout of which is shown in Figure 2 and the scale of which can be determined from Figure 4a. The aim was to compare the aerodynamic performance of a scale model of a typical rectangular, "brick"-shaped construction load (replicating a load profile most commonly lifted via a tower crane) against the aerodynamic performance of the scale model of the Lifting Wing in a range of wind speeds and yaw angles.

Figure 2. Loughborough university aeronautical and automotive engineering wind tunnel isometric.

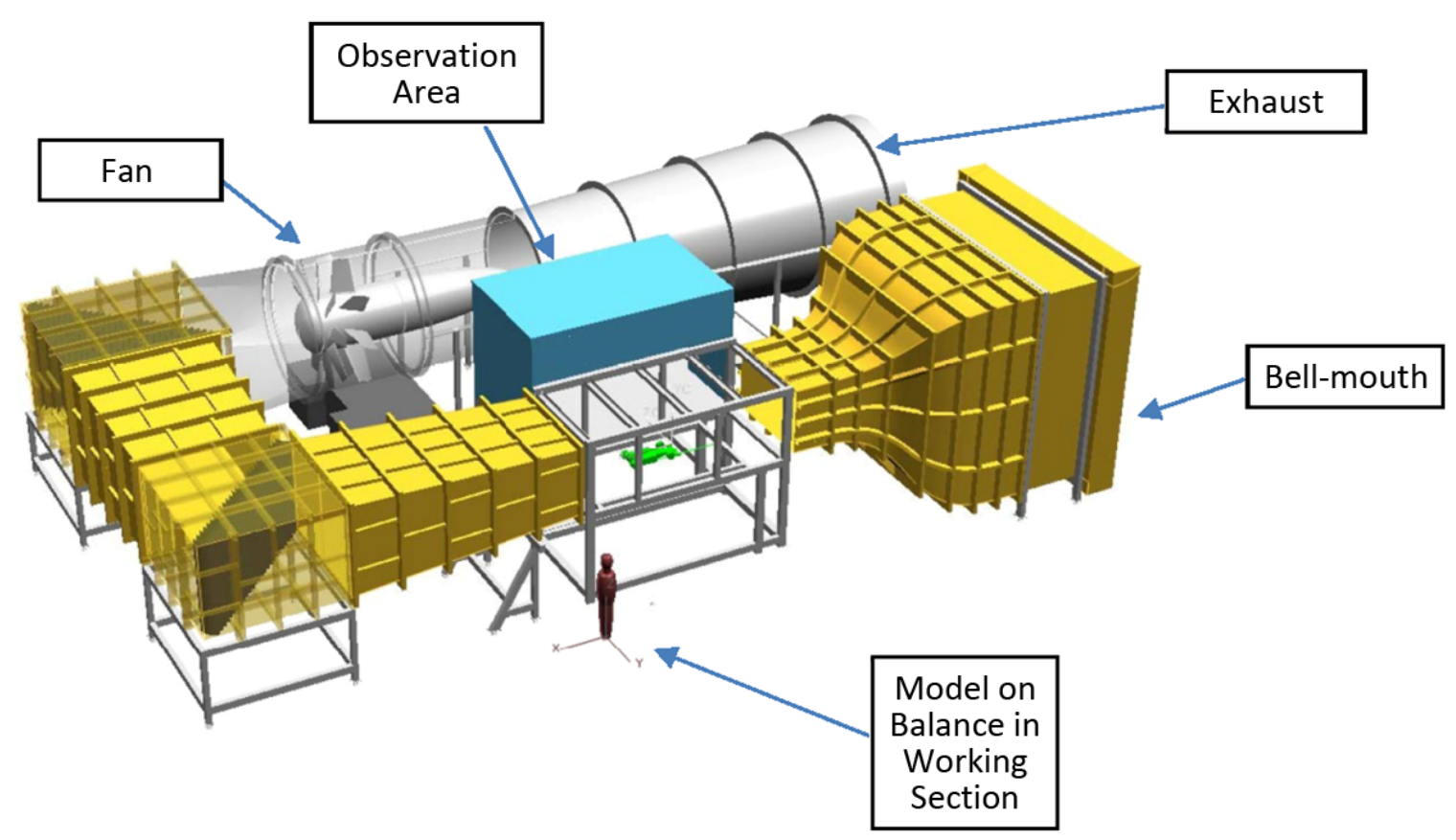


To ensure the test results are predicative of full-scale results, the tests were planned to be undertaken with a Reynolds number $(\mathrm{Re})$ as close to the calculated full-scale Wing, Re of $8.2 \times 10^{6}$, calculated for a wind speed of $20 \mathrm{~m} / \mathrm{s}$, where Re $=$ Inertia Force/Viscous Force $=($ Density $\times$ Velocity $\times$ Length)/absolute coefficient of Viscosity. If the model has the same Re as the full-scale application, then they are dynamically similar [18]. The non-dimensional function of Fluid Viscosity, Density, Pressure, and Temperature will be the same for the model and full scale. However, Re sweep tests of both models showed the Re became invariant above $1.5 \times 10^{6}$, allowing the results obtained to replicate the full-scale Lifting Wing in wind speeds of up to $90 \mathrm{mph}$ (current international standards for tower crane "in-service" wind speeds with no aerodynamic aid are up to $20 \mathrm{~m} / \mathrm{s}$ or $45 \mathrm{mph}$ ).

\subsection{Testing Method}

The scale model of the Lifting Wing was built to an accuracy of $\pm 1 \mathrm{~mm}$, with the design based on the NACA 0035 aerofoil. The chord length was $600 \mathrm{~mm}$, maximum width of $216 \mathrm{~mm}$ and height $200 \mathrm{~mm}$, with a cross-sectional area of $0.0432 \mathrm{~m}^{2}$. This equates to a 1:10 scale model of the full size Lifting Wing. The model construction was formed using a $2 \mathrm{~mm}$-thin plywood sheet laid over and fixed to a slim CNC cut plywood spar frame at the top and bottom of the wing, as shown in Figure 3a,b.

Figure 3. (a) Lifting Wing model and top mounting bracket; (b) Wing internal void, spar frame and brackets.

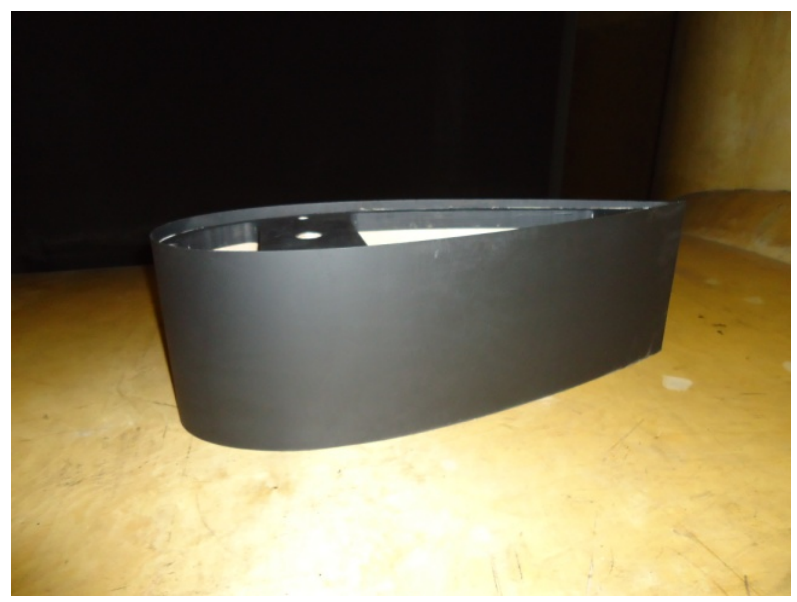

(a)

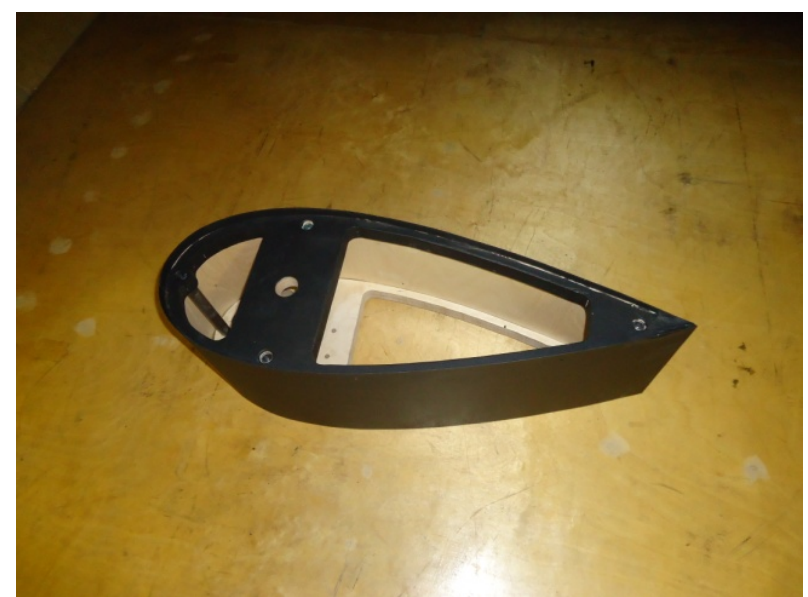

(b)

Similarly, the 1:10 scale model of the typical construction load, the "Brick", was built with the same technique, having a chord length of $600 \mathrm{~mm}$, maximum width of $210 \mathrm{~mm}$ and height of $200 \mathrm{~mm}$, giving a reference area of $0.043 \mathrm{~m}^{2}$.

It was initially anticipated that multiple sets of results would need to be taken, depending on the accuracy and repeatability of the obtained results. However the first series of test results showed good accuracy and repeatability (within 5\%) and a minor, but consistent level of asymmetry. This test series was run twice allowing the arithmetic mean to record the central tendency. The asymmetric tendency was subsequently determined as a feature of the tunnel and had been repeated in numerous wind tunnel test experiments undertaken by Aeronautical Researchers at Loughborough University and was quantified and accounted for, therefore deemed to be insignificant to the results. 
The wind tunnel test allowed quantitative data for drag, pitch, side force and other relevant forces acting on the Brick model and the Wing model at a range of wind speeds and yaw angles to be compared. These forces and their directional impact on the Wing are shown in Figure 6. These tests were conducted in parallel with flow visualisation observations at key stages of the testing to cross check the quantitative results and the logic behind conclusions drawn. Additionally, a preliminary dynamic test was also undertaken as a third method of cross checking results obtained from the first two methods, giving qualitative information in the form of a visual display of the Wing under freely suspended conditions reflecting, as closely as possible, the conditions of the full-scale Wing suspended by a tower crane. However, results obtained were indicative only, due to issues with model symmetry and difficulty finitely levelling the model. The dynamic test will be refined and re-run in the next stage of research.

\subsection{Test Summary}

The objective of this test was to generate quantitative data for the model's drag $(\mathrm{Cd})$, lift $(\mathrm{Cl})$ and pitching $(\mathrm{Cp})$ moments at varying degrees of yaw and wind speed. The wind tunnel test was designed to minimize systematic errors by considering and compensating for the most likely causes of error including model or tunnel asymmetry, error caused by the wind forces acting on the connection shaft between the model and the tunnel balance, plus random errors. The method of testing involved both the reference "Brick" model and the Lifting Wing being rigidly fixed by a steel connection shaft to the balance (Figure $4 \mathrm{~b}$ ), which is fitted into the floor of the working section of the tunnel. Once true zero (head-to-wind) position was established by undertaking a yaw sweep for each model, the tests were undertaken for each model in turn.

Figure 4. (a) LU AAE Wind Tunnel Bell-mouth and Exhaust; (b) Balance below Tunnel Working Section.

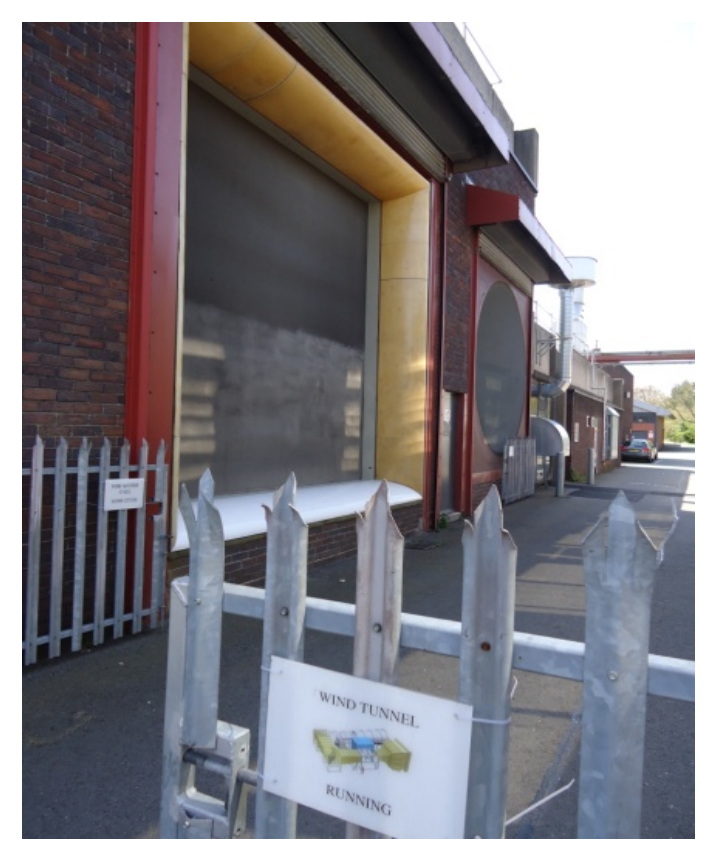

(a)

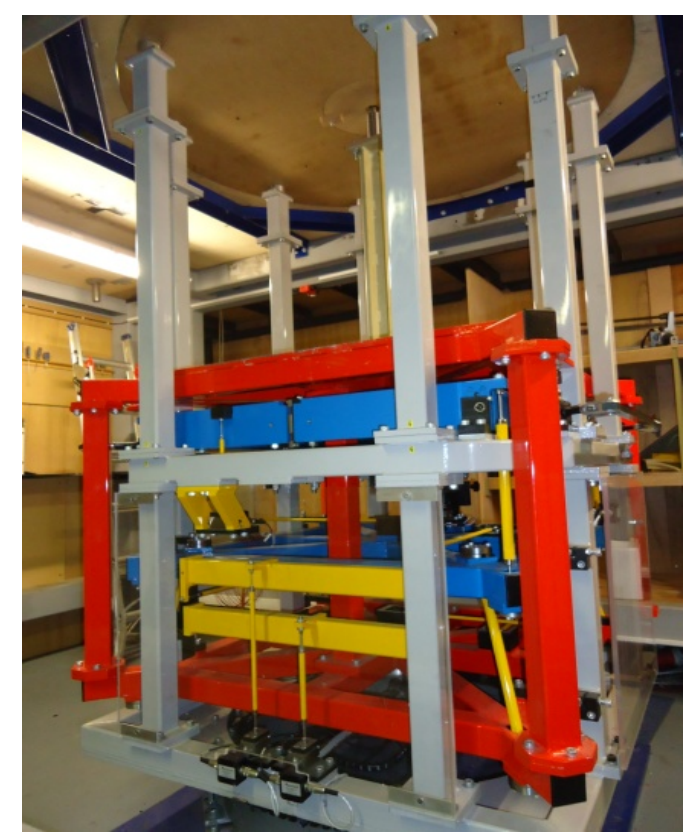

(b) 
The reference areas of the models, the wind speed, barometric pressure, air temperature, drag, lift, side-force, pitching moment, yawing moment and rolling moments, plus their coefficients, were recorded by the tunnel computer data logger at a range of wind speeds from zero to $40 \mathrm{~m} / \mathrm{s}$. The model was then rotated (yawed) on the balance through two degrees away from true zero and all measurements recorded. This was repeated by further $2^{\circ}$ increments up to $\pm 20^{\circ}$, then 1 degree increments up to a maximum of $\pm 25^{\circ}$ yaw. Tests for each model were re-run after powering down the wind tunnel (effectively re-setting, or zeroing the tunnel and its data logger) to determine the repeatability of results. All results taken were within 5\% of the initial result with no outliers, allowing the arithmetic mean to be utilised for the final result. Measurements for the Wing were compared to the reference Brick model, ultimately demonstrating the aerodynamic improvement of the Wing.

\subsection{Test Method}

- The steel connection shaft was mounted to the tunnel balance and the wind tunnel was run at $5 \mathrm{~m} / \mathrm{s}$ increments from zero up to $45 \mathrm{~m} / \mathrm{s}$ to determine forces due to shaft alone and allow balance results for each model to be adjusted for shaft effects. To refine these results, a replica support shaft of the same diameter as the one used to support each model was raised into the tunnel to a height of $450 \mathrm{~mm}$. Each model was then attached to the tunnel roof via the original support shaft and lowered until it was just clear of the replica shaft fixed to the balance. This gave a more accurate balance reading of the shaft value to be subtracted from each model measurements;

- The Brick model was mounted on the steel shaft fixed to balance. The maximum velocity, $V_{\max }$ was established by running wind tunnel from $0 \mathrm{~m} / \mathrm{s}$ at $5 \mathrm{~m} / \mathrm{s}$ incremental speeds, whilst ensuring drag, lift, side-force, pitch, yaw and roll loads did not exceed $90 \%$ of the limit of the wind tunnel balance. This was repeated for the Wing model, resulting in a $V_{\max }$ of $40 \mathrm{~m} / \mathrm{s}$, with generated forces at just over $85 \%$ of the balance limit for the Brick model;

- A Reynolds Number (Re) sweep for the Brick at zero degrees yaw, over incremental wind speeds from 0 to $40 \mathrm{~m} / \mathrm{s}$ was run allowing the calculation of the Re for the range of wind speeds, plotted to determine the minimum wind speed at which the Re becomes a constant (thus replicating full-scale results). This was repeated for the Lifting Wing. Resulting Re values shown in Figure 5, demonstrated that above Re of 600,000 there is relatively little Re effect and results are as close to full scale as possible;

- A series of tests for both the Brick and Wing were run, recording forces graphically shown in Figure 6, the results of which produced following graphs: Brick Yaw Angle versus CDrag for $30 \mathrm{~m} / \mathrm{s}$ and $40 \mathrm{~m} / \mathrm{s}$; Brick Yaw Angle versus CLift for $30 \mathrm{~m} / \mathrm{s}$ and $40 \mathrm{~m} / \mathrm{s}$; Brick Yaw Angle versus CSideforce for $30 \mathrm{~m} / \mathrm{s}$ and $40 \mathrm{~m} / \mathrm{s}$; Brick Yaw Angle versus CPitch for $30 \mathrm{~m} / \mathrm{s}$ and $40 \mathrm{~m} / \mathrm{s}$; Wing Yaw Angle versus CDrag for $30 \mathrm{~m} / \mathrm{s}$ and $40 \mathrm{~m} / \mathrm{s}$; Wing Yaw Angle versus CLift for $30 \mathrm{~m} / \mathrm{s}$ and $40 \mathrm{~m} / \mathrm{s}$; Wing Yaw Angle versus CSideforce for $30 \mathrm{~m} / \mathrm{s}$ and $40 \mathrm{~m} / \mathrm{s}$; Wing Yaw Angle versus CPitch for $30 \mathrm{~m} / \mathrm{s}$ and $40 \mathrm{~m} / \mathrm{s}$. 
Figure 5. (a) Brick Re versus Cd; (b) Wing Re versus Cd.

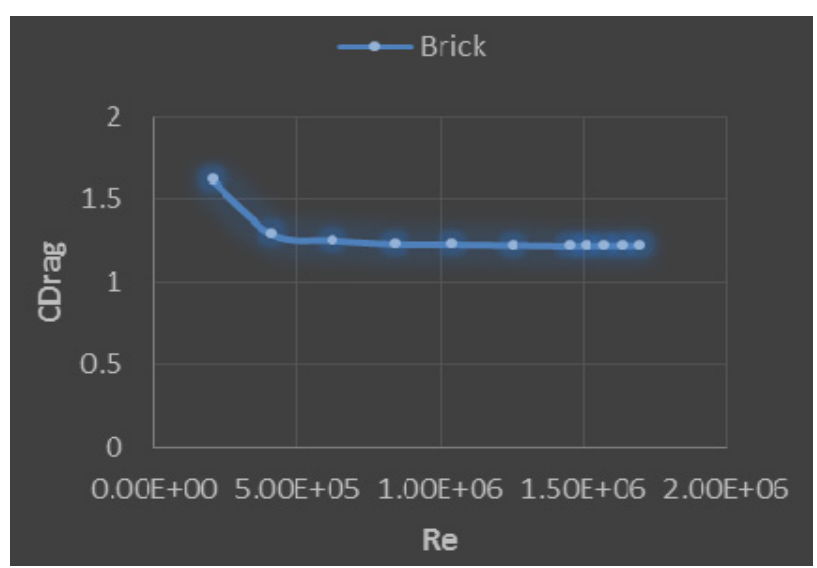

(a)

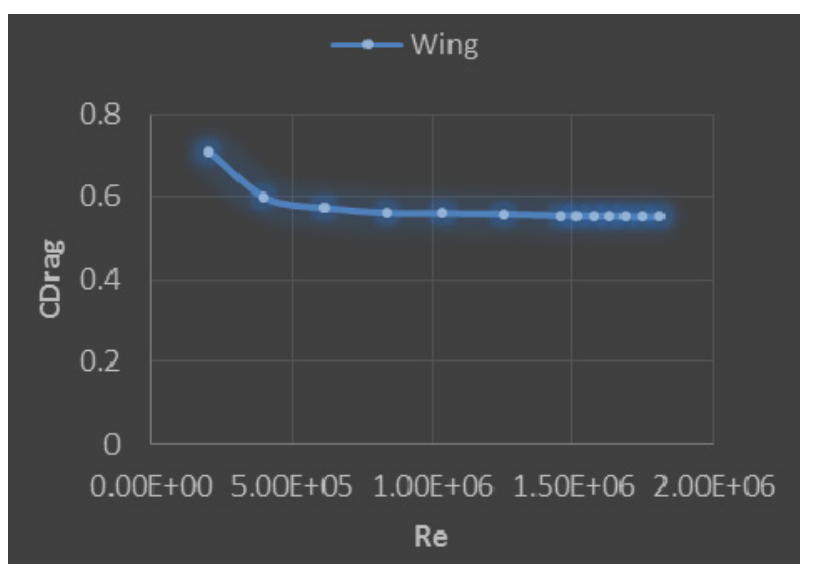

(b)

Figure 6. Wind force coefficients on the Lifting Wing.

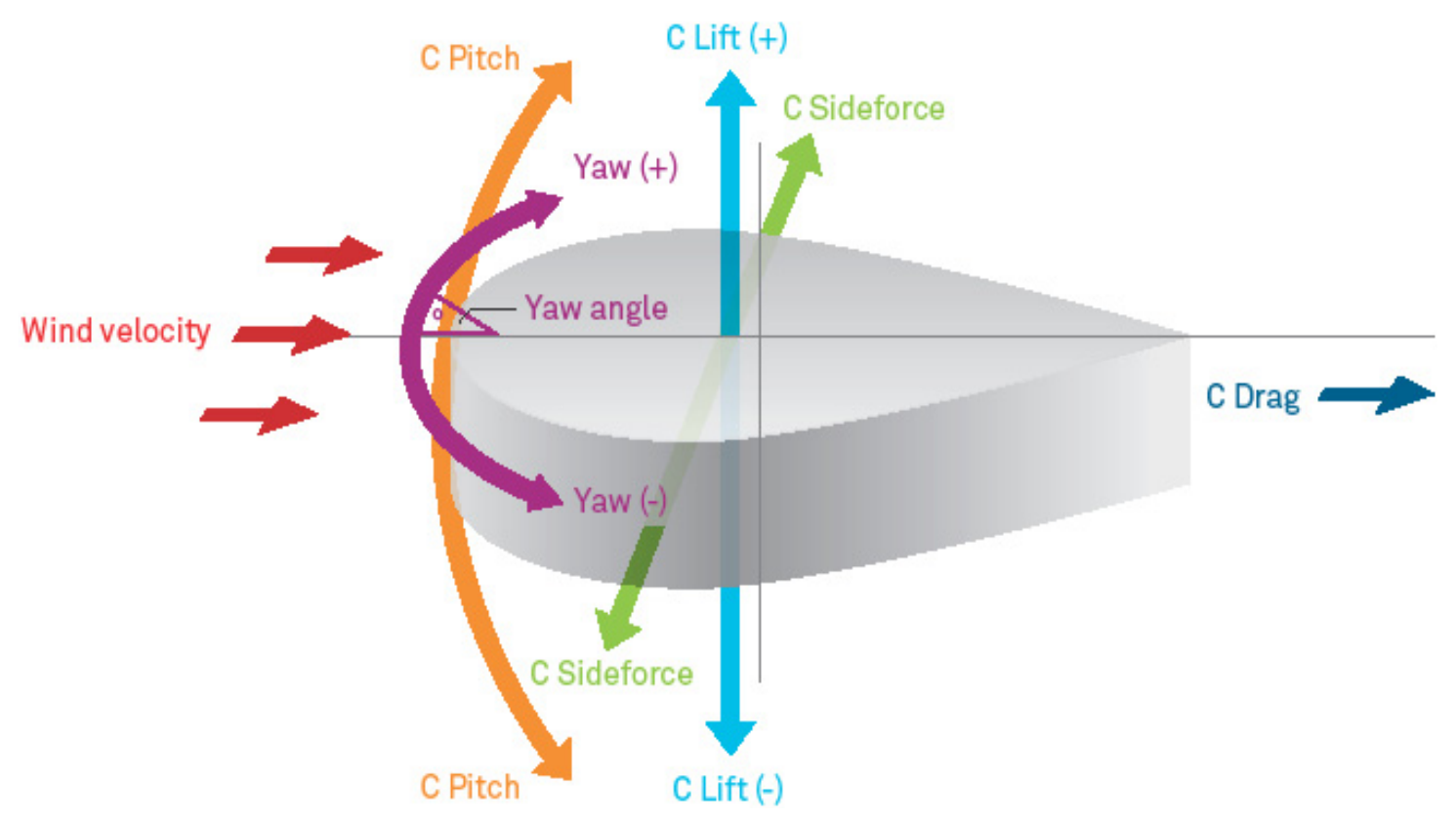

\subsection{Test Results}

An overlay of the two crucial sets of results for the Wing and Brick Yaw Angles versus CDrag at $30 \mathrm{~m} / \mathrm{s}$ and $40 \mathrm{~m} / \mathrm{s}$, and the Wing and Brick Yaw Angles verses CLift at $30 \mathrm{~m} / \mathrm{s}$ and $40 \mathrm{~m} / \mathrm{s}$ were graphically plotted, shown in Figure 7a,b.

The primary conclusions drawn from the CDrag overlay of the Wing and Brick are:

- The Wing profile had a dramatically lower overall drag profile (in excess of 50\% less CDrag than that of the Brick), hence significantly less drag load would be induced on the cable and the crane, in all wind conditions;

- The Brick results plotted graphically exhibit a deep V, which shows a relatively large sensitivity to wind direction changes, which dramatically increase drag- and swing-induced loading, hence load on the crane. This feature is shown by comparing flow visualisation Figure $8 \mathrm{a}$ at zero degrees showing a wide flow attachment line one third back from the nose 
and Figure $8 \mathrm{~b}$ at 10 degree offset, showing a more defined flow attachment line further forward, directly behind the front corner. This increases the size of the wake area and reverse flow behind the Brick, thereby increasing drag;

- By comparison, the Wing plotted results exhibit a smooth, shallow curve, showing relative insensitivity to changes in wind direction, with less drag- and swing-induced forces, hence a more stable flight. This is demonstrated by comparing the Brick Figure $8 \mathrm{~b}$ and the Wing Figure 11a at 10 degree offset. This shows smooth attachment lines running to the sharp trailing edge of the Wing, limiting the separated flow, or wake area behind the Wing, hence low drag;

- The tendency for drag to increase as yaw angle increases tails off earlier with the Wing, reaching a maximum at around $\pm 12^{\circ}$ (See Figure 7a) due to the sharp trailing edge and smooth flanks, whereas the Brick drag forces continue to increase as yaw angle increases to a maximum at around $\pm 18^{\circ}$ as the wake area behind the Brick and reverse flow continues to grow. This demonstrates the improved stability generated by the Wing, reducing drag-imposed loads on the crane in higher wind speed and with changeable wind directions.

The primary conclusions drawn from the CLift overlay of the Wing (with Brick load inside the Wing) and Brick are:

- Lift forces generated on both models are less than a 10th of magnitude of drag forces and therefore its influence is likely to be less significant;

- The Wing profile has a lower overall lift profile (less than $1 / 4$ th of the lift of the Brick at higher yaw angles) hence significantly less rise-and-fall load would be induced on the cable and crane in higher wind conditions. This feature is most clearly demonstrated by comparing flow visualisation Figure $9 \mathrm{a}$, the leeward side of the Brick at $-25^{\circ}$. It shows a more pronounced flow along the top and bottom edges, which become more dominant at the higher yaw angle. In contrast, the Wing (Figure 12a) shows the leeward side of the Wing at $-10^{\circ}$ (which was almost identical to the Wing at $-25^{\circ}$ ). The Wing shows more fractured, multiple flow separation lines running from the nose toward the tail that drop away much earlier. These markedly differing flow features would explain the differing lift forces generated on each model;

- The Brick exhibits a sharp and deep W profile, which signifies sensitivity of this shape to increasing wind yaw angle, dramatically increasing lift- and fall-induced loading, hence load on the crane. This would result in a rotation of the load when freely suspended from a crane, causing safety issues when trying to fly and land the load safely;

- The Brick also shows increasing sensitivity to higher wind speed as the results for $30 \mathrm{~m} / \mathrm{s}$ and $40 \mathrm{~m} / \mathrm{s}$ diverge at higher yaw angles producing unstable flight characteristics as these factors increase;

- By contrast, the Wing exhibits a smooth, shallow curve, showing relative insensitivity to changes in wind yaw angle or wind speed, hence less rise- and fall-induced forces and more stable flight characteristics. 
Figure 7. (a) Wing and Brick Yaw Angles versus CDrag for $30 \mathrm{~m} / \mathrm{s}$ and $40 \mathrm{~m} / \mathrm{s}$; (b) Wing and Brick Yaw Angles versus CLift for $30 \mathrm{~m} / \mathrm{s}$ and $40 \mathrm{~m} / \mathrm{s}$.

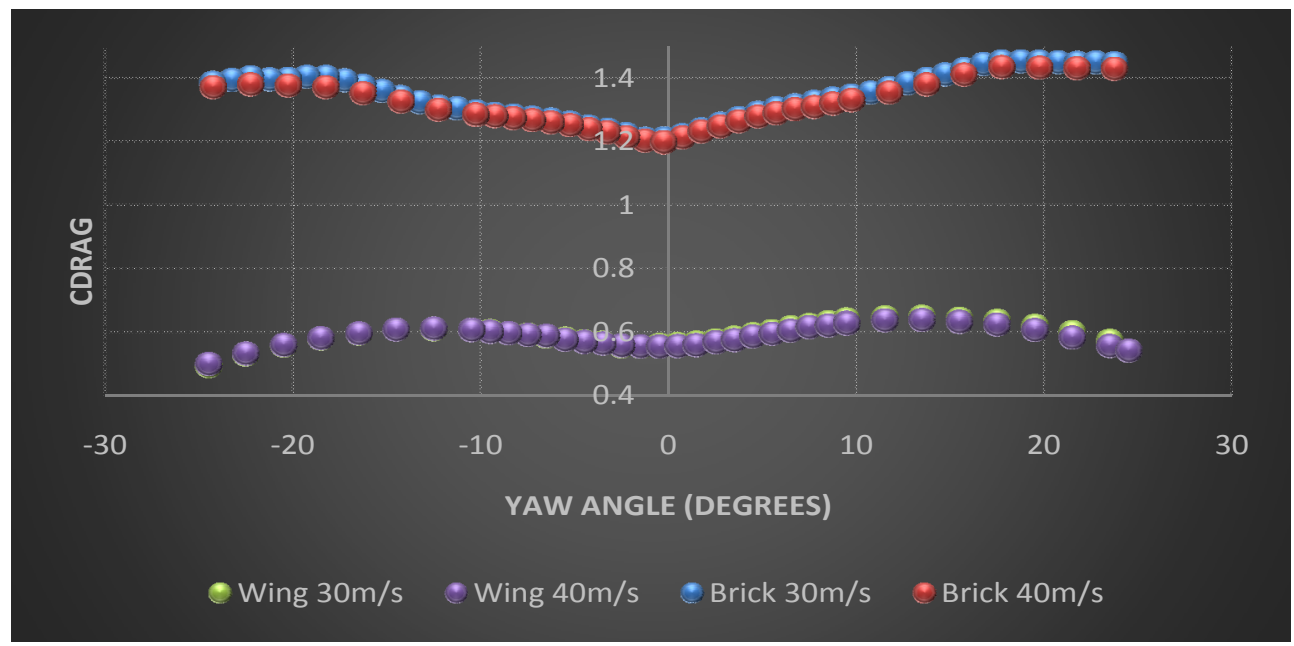

(a)

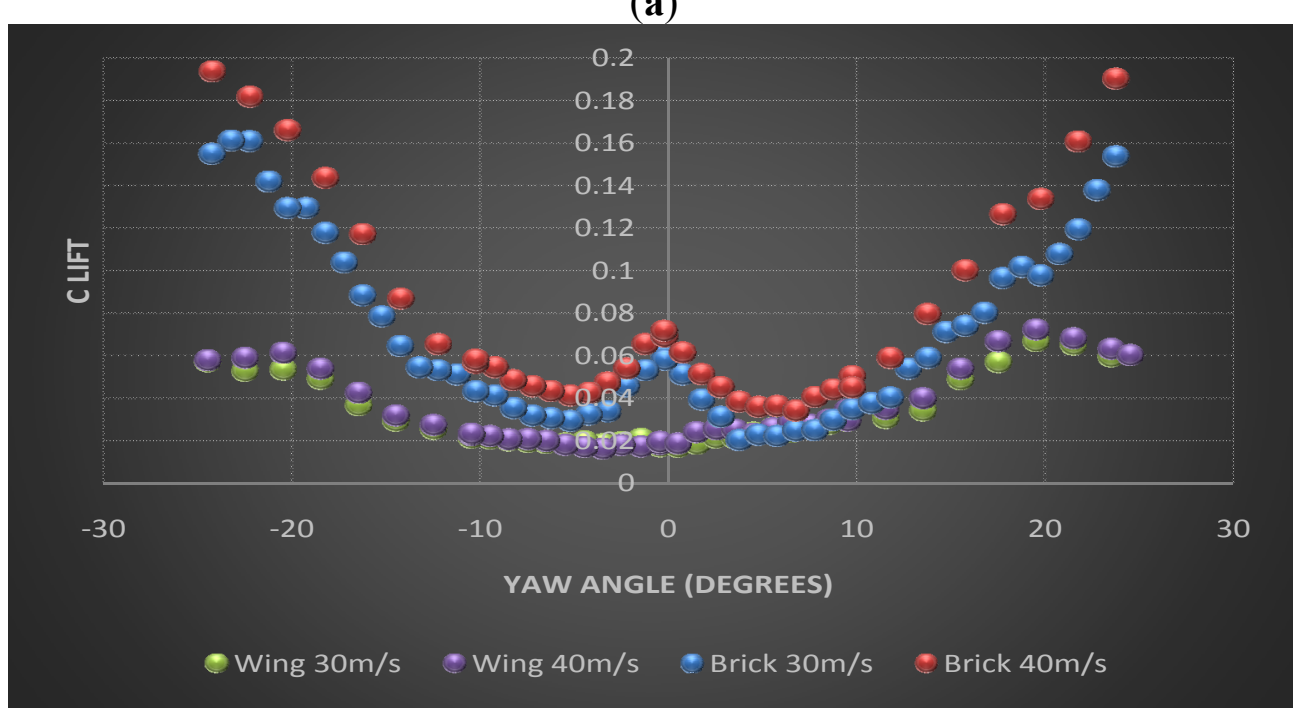

(b)

\subsection{Wind Tunnel Test Conclusion}

Each of these tests were run twice and results showed good repeatability of generated quantitative data for both model's drag and lift forces at varying degrees of yaw and wind speeds. The arithmetic mean was taken to give the central tendency as there were no outlier results taken (all values were within $5 \%$ of the initial the result). Side force and pitching moment were also measured in this method, but ultimately deemed less critical, being relatively similar for both models, with slightly less pitching moment generated by the Wing under extreme yaw angles and slightly higher side forces generated by the Wing at higher yaw angles, creating a restoring yawing moment (self-correcting characteristic), ultimately producing a stable flight in changing wind direction. These mean results demonstrated significantly improved aerodynamic characteristics of the Wing, resulting in significant reductions in critical forces generated by wind acting on the Wing, hence forces imposed on the tower crane at full scale. These results point toward the Wing assisting the tower crane operator in their control of the tower crane in higher wind-speed conditions experienced on a construction site, thereby delaying his 
decision to take the crane out of service at a wind speed significantly lower that the manufacturers prescribed "out of service" speed.

These conclusions were further tested by conducting flow visualisation analysis of the Wing and Brick at varying wind speeds and yaw angles in the wind tunnel, discussed below.

\subsection{Flow Visualisation}

A series of flow visualisation photographs of the Brick and Wing models were taken at key stages in the wind tunnel testing for each model to allow comparison of aerodynamic flow around the models. These were achieved by coating the Brick and Wing models with a mixture of titanium dioxide, paraffin and linseed oil, and capturing the resultant flows at true zero degrees, plus and minus $10^{\circ}$ and plus and minus $25^{\circ}$ yaw at varying wind speeds. A demonstrative selection of flow images are given in Figures $8-12$. Wind is flowing from left to right in all figures with exception of $11 \mathrm{a}, \mathrm{b}$, where it is right to left. Windward is a $(+)$ yaw angle from true zero (head-to-wind flow), showing the side facing into the wind and leeward a (-) yaw angle showing the side in the wind "shadow".

Figure $8 \mathrm{a}$ is a flow visualisation photograph of the Brick at true zero to the wind flow and is viewed from the leading edge corner. The wind flow impacts on the flat face and spreads out towards all four sides of the Brick. The flow separates at the four edges and a large wake is formed behind the Brick. This wake is responsible for the large coefficient of drag seen in the wind test results. The wide flow separation line running from the top to bottom of the Brick at the point where the vortices at each side of the Brick, created by the blunt nose, reverse the flow back toward the front of the Brick where it meets the wind flow spilling around the nose corner and become entrained in the wake. This causes the flow to stall and gravity then drags the mixture down. These flow patterns should occur on all four sides (excepting gravitational effect).

Figure $8 \mathrm{~b}$, taken from the same position, but with the Brick at $+10^{\circ}$ yaw (windward), shows the reverse flow separation line being pushed much nearer the front corner of the nose. This is caused by a more dramatic meeting of the vortex flow (which has increased force due to the $+10^{\circ}$ yaw) and the frontal flow spilling around the nose corner. It also shows flow detachment approximately mid-way along the Brick, with some flow being pushed toward the nose and some being pushed toward the rear of the Brick.

Figure 9a shows the leeward side of the Brick at $-25^{\circ}$ yaw. There is more pronounced flow along the top and bottom edges, which becomes more dominant at the higher offset angle. The flow has separated at the edge on the front face, but the reverse flow is now three dimensional, flowing towards both the front and side edges. The flow towards the sides meets flow spilling around from the top and separates at the white line and is entrained into the wake. The separation line at the lower edge is smaller due to gravity. This will contribute to the lift force seen in wind test results. The resulting wake will be more pronounced on this side.

Figure $9 \mathrm{~b}$ shows the windward side of the Brick at $+25^{\circ}$ yaw. The flow is pushing from the front centre in three dimensions toward the top, bottom and rear trailing edges remaining attached along the flank. The resulting wake will be less pronounced on this side. 
Figure 8. (a) Brick at $0^{\circ}, 40 \mathrm{~m} / \mathrm{s} ;$ (b) Brick at $+10^{\circ}, 40 \mathrm{~m} / \mathrm{s}$.

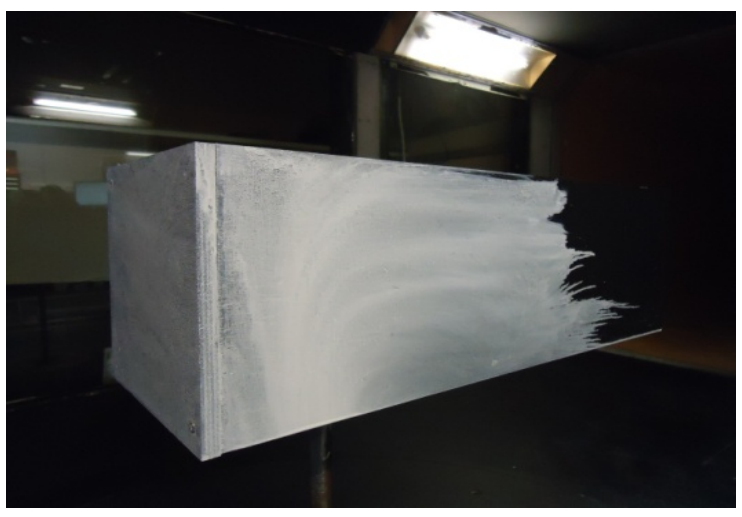

(a)

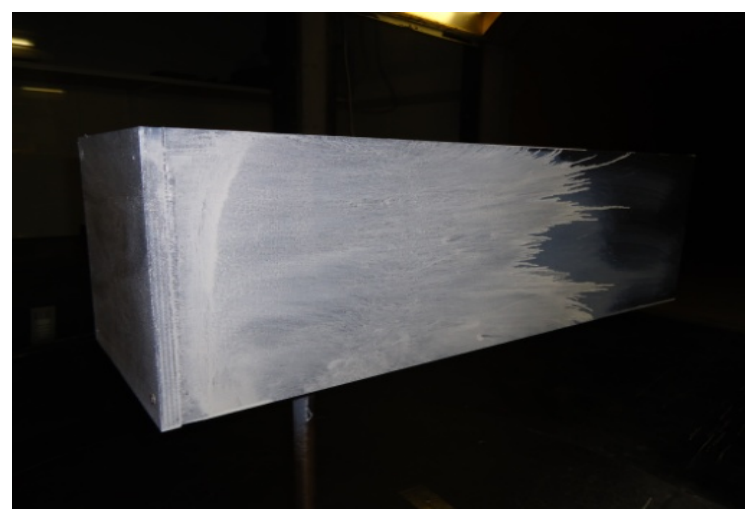

(b)

Figure 9. (a) Brick nose at $-25^{\circ}, 40 \mathrm{~m} / \mathrm{s}$; (b) Brick tail at $+25^{\circ}, 40 \mathrm{~m} / \mathrm{s}$.

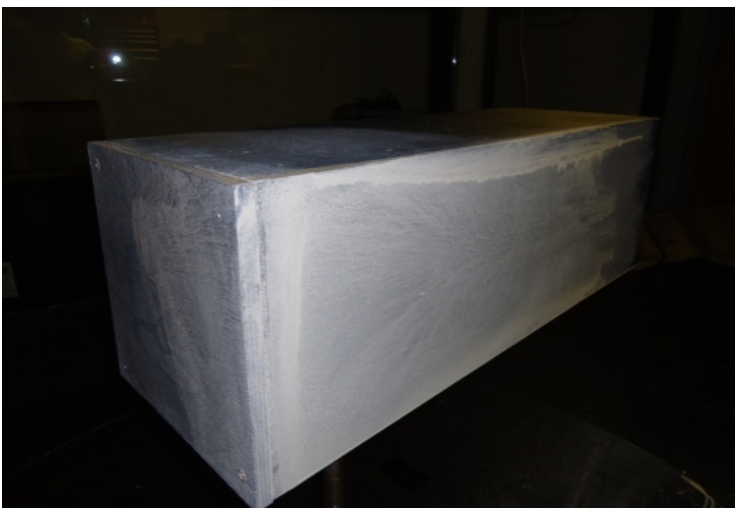

(a)

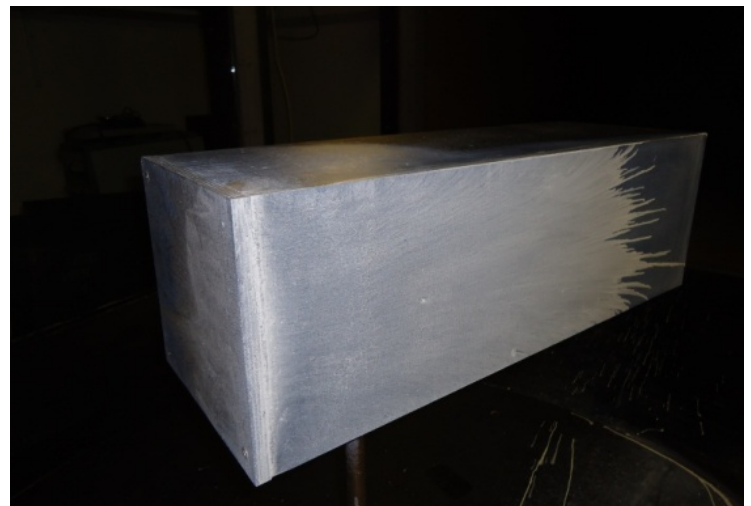

(b)

Figure 10a shows the Lifting Wing model at $0^{\circ}$. The Wing has a very low aspect ratio and the flow around the trailing edge is highly significant. The extent of the separated flow producing the wake is much smaller than for the Brick, resulting in a significantly lower drag. The flow is attached from the nose and forms two strong flow separation lines running from the nose toward the tail. These drop away toward the bottom rail at the tail of the Wing as flow rate reduces and gravitational forces take over. The collection of mixture at approximately one third along from the nose of the Wing is at its widest point. This may indicate a nearing of flow separation at this potential transition point, but the flow successfully negotiates the curve of the Wing and continues in laminar flow along the Wing's surface until it nears the tail's trailing edge.

Figure $10 \mathrm{~b}$ shows this effect from the tail view. It shows the flow reducing as it runs along the Wing and gradually falling under gravitational force as it nears the narrowest point, the trailing edge. It then separates, creating a relatively small wake.

Figure 11a shows the Wing at $+10^{\circ}$ yaw, where it exhibits a more singular flow separation line running from the nose toward the tail. This drops away more gradually, only hitting the bottom rail at the tail intersection point. The collection of mixture has moved further back from the nose of the Wing and is now behind the point of maximum Wing width. This indicates the potential transition point has moved further back due to the increased windward yaw angle, hence increased flow across this face of the Wing. Again, it does not actually separate at this point and continues toward the tail in laminar 
flow until it nears the tail trailing edge, but at a point further from the tail, indicating that the turbulent boundary layer is occurring earlier. The flow patterns are very similar to the $0^{\circ}$ case which explains why the drag appears to be relatively invariant for the Wing.

Figure $11 \mathrm{~b}$ shows this effect from the tail view and shows the flow reducing and falling under gravitational force as it travels to the trailing edge, but that it separates earlier to become turbulent flow.

Figure 10. (a) Wing nose at $0^{\circ}, 40 \mathrm{~m} / \mathrm{s} ;$ (b) Wing tail at $0^{\circ}, 40 \mathrm{~m} / \mathrm{s}$.

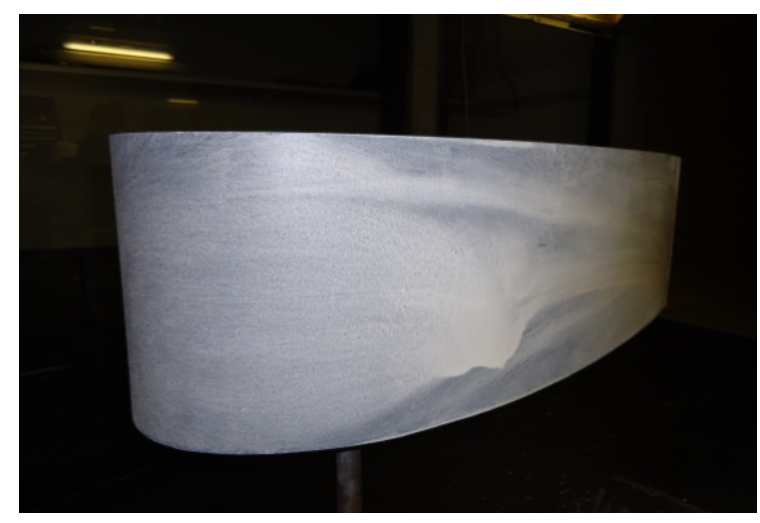

(a)

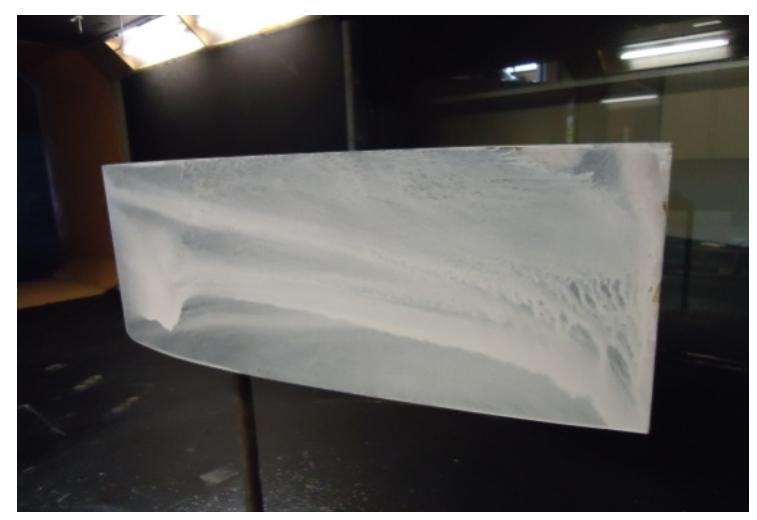

(b)

Figure 11. (a) Wing nose at $+10^{\circ}, 40 \mathrm{~m} / \mathrm{s}$; (b) Wing tail at $+10^{\circ}, 40 \mathrm{~m} / \mathrm{s}$.

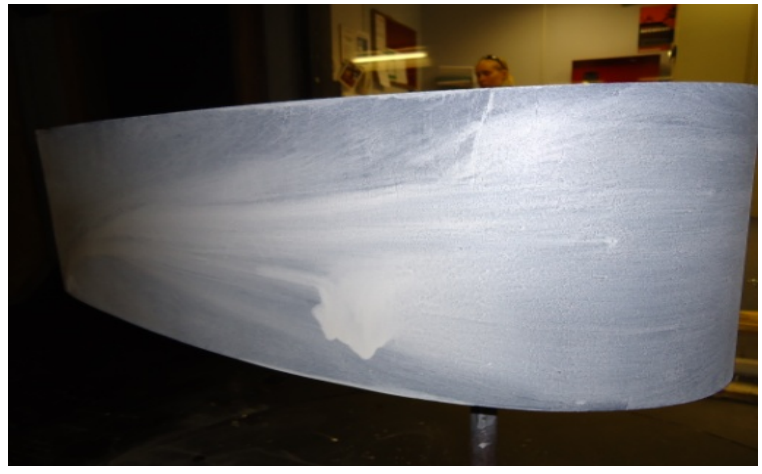

(a)

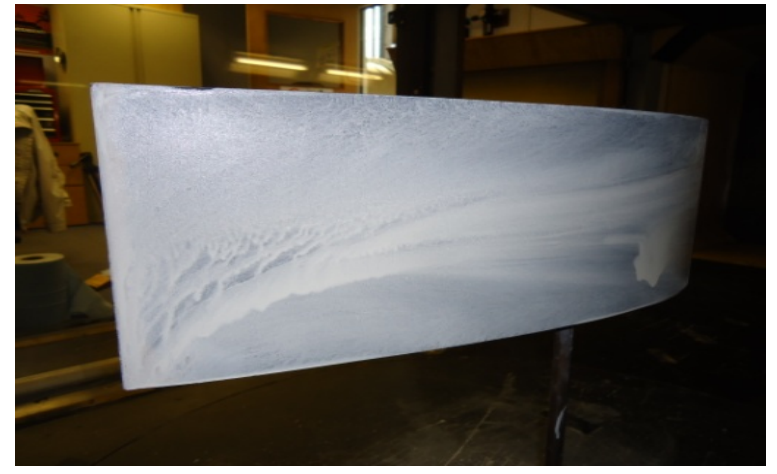

(b)

Figure $12 \mathrm{a}$ shows the Wing at $-10^{\circ}$ yaw, leeward side viewed from the nose. The Wing now exhibits more fractured, multiple flow separation lines running from the nose toward the tail that drop away much earlier, demonstrating that the flow rate is much reduced across this face and gravitational forces take over earlier. The collection of mixture has moved further toward the nose and is now in front of the maximum Wing width position. This indicates the transition point has moved forward due to the more turbulent, reduced flow formed in the wind shadow. It now actually begins to partially separate at this point, whilst some flow does continue toward the tail in laminar flow but then separates at a point much closer to the midpoint of the Wing, indicating that the turbulent boundary layer is occurring much earlier. This effect would create the restoring turning moment in the Wing, ensuring it returns to a zero yaw position (nose-to-wind).

Figure $12 \mathrm{~b}$ is the tail view and shows the flow reducing and falling under gravitational force much earlier as it travels along the Wing and separates earlier to become turbulent flow across the rear third of the Wing. 
Flow visualisation pictures of the Wing at $\pm 25^{\circ}$ yaw showed no significantly differing patterns to the $\pm 10^{\circ}$ discussed above. This fact demonstrates that the drag is relatively invariant for the Wing, whilst exhibiting significantly less drag variation than the Brick.

Figure 12. (a) Wing nose at $-10^{\circ}, 40 \mathrm{~m} / \mathrm{s}$; (b) Wing tail at $-10^{\circ}, 40 \mathrm{~m} / \mathrm{s}$.

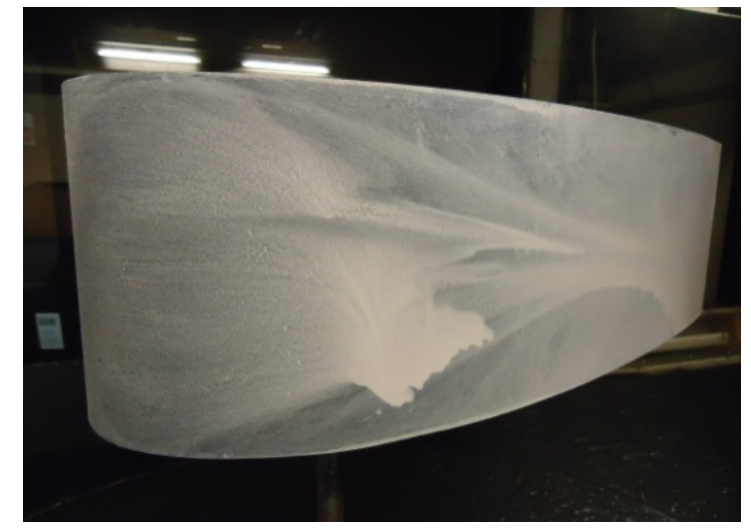

(a)

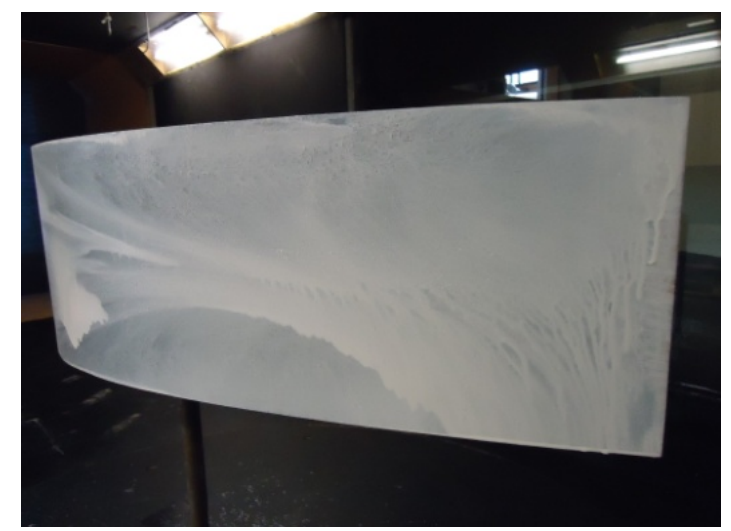

(b)

\subsection{Flow Visualisation Conclusion}

These flow visualisations show a relatively clean, stable flow over the Wing at varying degrees of yaw, demonstrating stable and predictable aerodynamic behaviour. The significantly reduced drag of the Wing compared to the Brick, along with the Wing's invariance of drag at higher yaw angle, are the key factors in proving the ability of the Wing to operate safely in higher and gustier wind conditions than a standard construction load. These observations correlate with the quantitative data taken during wind tunnel testing and reinforce the characteristics of stable and improved aerodynamic behaviour of the Wing over the Brick. These results were further tested by conducting a dynamic test of the Wing suspended in the wind tunnel.

\subsection{Preliminary Dynamic Test}

The objective of this dynamic test was to conduct visual analysis of the Wing's aerodynamic characteristics under conditions reflecting, as closely as possible, suspension of the Wing from a tower crane cable in wind conditions likely to be experienced on a tall building site. No quantitative measurements could be taken during this test, as it was purely a visual analysis of the Wing's aerodynamic performance.

It was noted during this test that error in model symmetry and the inability to finitely level the model affected the results and would need further refinement to achieve an accurate replication of full-scale results.

The Wing model was freely suspended by three, $2 \mathrm{~mm}$ in diameter multi-strand steel cables, each with a $10 \mathrm{~kg}$ breaking strain. These were mechanically fixed to the top edge of the model, one directly above the centre of the nose and two equally positioned on the top edge either side of the Wing, behind the widest section of the Wing. The centre line of the three wires were over the centre of gravity of the model. These wires were sufficiently long to allow the Wing to be suspended in the centre of the tunnel working section, with the wires running through a hole in the roof of the tunnel and 
mechanically fixed externally to support the dead and live loads of the model during testing (Figure 13a). This suspension method replicates the envisaged method of suspension of the full-scale Wing from a tower crane.

A series of videos were taken to record the behaviour of the Wing under increasing wind speeds from 0 to $12 \mathrm{~m} / \mathrm{s}$. These tests were then repeated with loads added inside the Wing ( $1 \mathrm{~kg}$ metal plates fixed inside the wing profile) to replicate 1, 2 and 3 tonne loads on a full-scale Wing (Figure 13b). Observations were made on Wing stability and flight behaviour from the side and roof windows of the tunnel working section.

Figure 13. (a) Wing Suspended for Dynamic Test; (b) Wing with Internal Load.

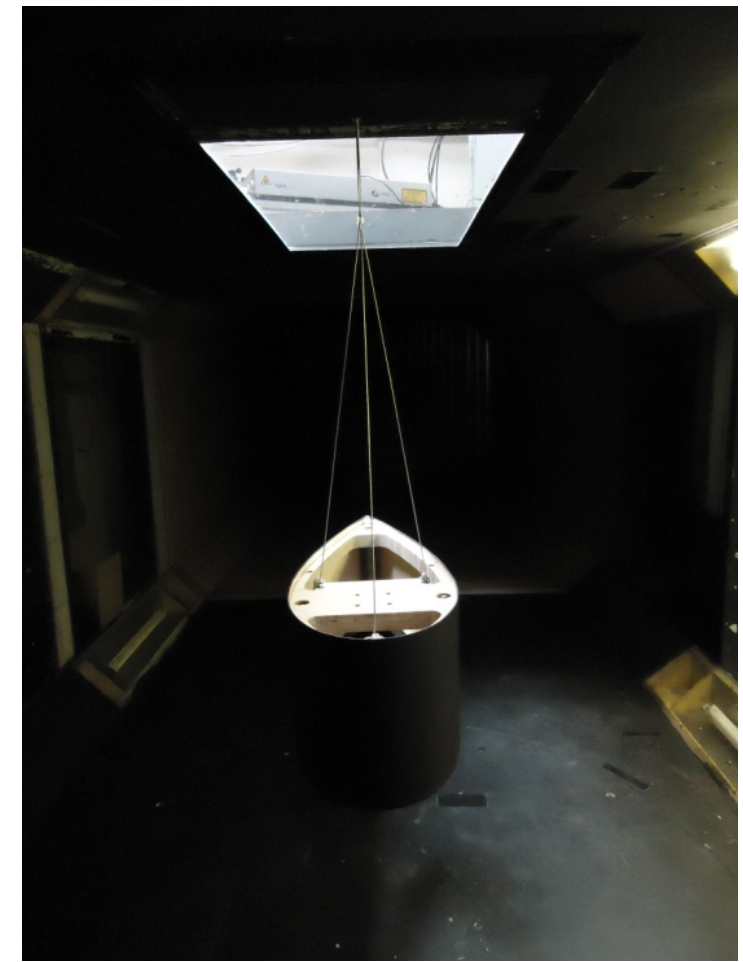

(a)

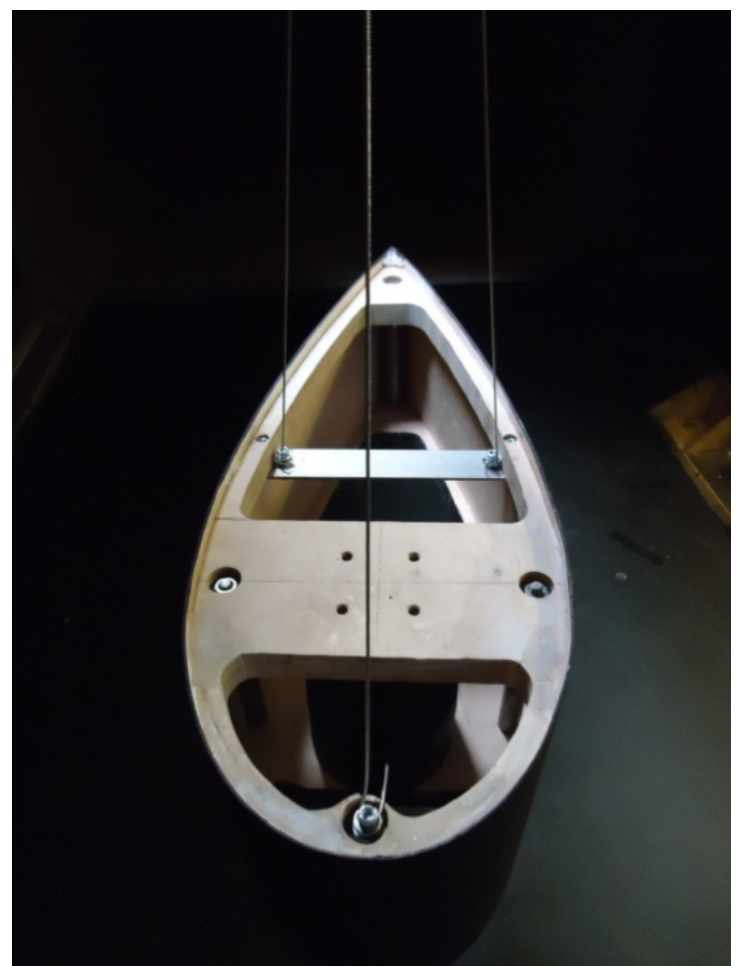

(b)

\subsection{Dynamic Test Observations}

The test was initially run with no internal load and videoed from the side window of the tunnel. The Wing remained relatively static as the wind speed was increased from $0 \mathrm{~m} / \mathrm{s}$ to $9 \mathrm{~m} / \mathrm{s}$, swinging slowly back by approximately $5^{\circ}$ from the vertical as wind speed increased to $9 \mathrm{~m} / \mathrm{s}$. At $10 \mathrm{~m} / \mathrm{s}$ the nose of the Wing was observed to begin to move horizontally from left to right, stop and then return from right to left through the head-to-wind at $0^{\circ}$ yaw. This repeating oscillation increased in yaw angle as the wind speed was increase to a maximum of $12 \mathrm{~m} / \mathrm{s}$, whereupon the nose of the model, viewed from above, moved left to right whilst swinging forward and back, describing a repeating infinity $(\infty)$ symbol movement over a distance approximately equal to half the length of the model $(300 \mathrm{~mm})$. This oscillation reduced as the wind speed was reduced to $9 \mathrm{~m} / \mathrm{s}$, whereupon the model became relatively static again, holding the $5^{\circ}$ inclined position. 
This test was repeated with a load of $2 \mathrm{~kg}$ fixed inside the Wing. It repeated the pattern of the first test, with the exception that the oscillation began at the increased wind speed of $11 \mathrm{~m} / \mathrm{s}$ and diminished as the wind speed was reduced below $11 \mathrm{~m} / \mathrm{s}$.

Finally, a load of $3 \mathrm{~kg}$ was fixed inside the Wing, again repeating the pattern of the first and second tests, with the exception that the oscillation began at an increased wind speed of $12 \mathrm{~m} / \mathrm{s}$ and diminished when wind speed was reduced below $12 \mathrm{~m} / \mathrm{s}$.

The initial movement of the nose from left to right was deemed to be caused by a lack of absolute symmetry of the model and it being slightly out of level horizontally due to unequal lengths of its three suspension cables. These small errors create a gradually increasing turning moment on the model as the wind speed increases. However, this also demonstrates the Wing's self-correcting characteristic, producing stability of flight at full scale, as this would ensure a slowly correcting nose-to-wind position of the Wing, desirable in changeable, gusty wind conditions typified on congested city-centre tall building sites.

\subsection{Implications of Results on Wing Design}

This preliminary dynamic test demonstrated that the full-scale Lifting Wing would need to be made symmetrically, ideally utilising vacuumed formed thermoplastic technology or moulded carbon-fibre-reinforced polymer, plastic or thermoplastic giving the added benefits of a higher strength-to-weight ratio and greater ability to withstand impact deformation. Residual error could be corrected by adding a top mounted vertical stabilising fin, fixed above the trailing edge of the Wing. The dynamic test also demonstrated the need for finite adjustment of suspension cables to ensure truly level flight. Following this paper's publication, this dynamic test will be further refined by the introduction of turnbuckles on each of the three suspension wires above the tunnel, allowing finite adjustment of each cable length, and hence achieving true horizontal suspension of the model in the tunnel.

This test also demonstrated the proportional relationship of increasing load to more stable flight - the greater the load carried inside the Wing, the less effect the non-symmetrical features of the model had on the stability of the flight in increased wind speed. It also proved that the ultimate wind speed in which stable flight could be achieved would be directly related to the size of the load carried inside the Wing.

\section{Overall Conclusions}

The wind tunnel test quantitative data correlates with the flow visualisation and preliminary dynamic test observations. These reinforce the primary Wing characteristics of reduced drag in excess of $50 \%$ lower than the Brick and of side forces on the Wing creating a restoring moment when flying in changeable wind direction conditions, giving a desirable nose-to-wind behaviour. These key characteristics combine to reduce induced loads on the tower crane and produce stable improved aerodynamic behaviour of the Wing when compared to typical construction loads.

This demonstrates that the Wing achieves its primary purpose of increasing the ability to lift construction materials safely in higher and more gusty wind-speed conditions than is currently achievable. Therefore, the Lifting Wing design, if used on a tower crane of a tall building, should create a valuable contribution in mitigating the effect of wind causing critical path delay during the 
construction of a tall building, potentially reaping substantial time and cost savings. This knowledge and benefit could be transferable internationally as, without exception, tall buildings across the world are built using tower cranes which are negatively affected by wind during the build period, delaying completion, frustrating builders from completing on time and budget and ultimately, owners from occupying their new tall buildings. These positive results will be further demonstrated by future studies utilising a full-scale Lifting Wing on a tower crane, discussed in the following section.

\section{Further Work}

Following running the refined dynamic test discussed above, the final stage of the Wing development will be undertaken with assistance from the authors' sponsoring company involving the construction of a full-scale Wing and its dynamic testing utilising a Saddle Jib or Luffing Jib Tower Crane. In this test, an experienced tower crane operator will lift a rectangular "Brick"-shaped reference load in wind conditions approaching industry-recognised winding-off speeds. The load will then be placed inside the full-scale Wing and lifted in the same wind conditions. The operator will note flight characteristics of each lift and determine the increased wind speed in which the Wing can still be lifted safely. This qualitative analysis will rely on the feedback from the operator, rather than on any measured force data. However it is exactly this operator analysis that is used across the industry to determine the safe limit of lifting by cranes on every site the world over. If tower crane operators feel the Wing allows extended lifting in higher wind conditions, then it will have succeeded.

An international patent has been applied for covering the Lifting Wing and the research that has been undertaken to date.

\section{Author Contributions}

This paper describes an element of the doctoral research conducted at Loughborough University in partnership with Lend Lease for the award of Engineering Doctorate. Ian Skelton was the Research Engineer and undertook the majority of the primary work. The co-authors of this paper are the EngD supervisory team, augmented as the project progressed due to staff movements. All supervisors contributed to manuscripts as the paper was being developed and reviewed. Peter Demian was the principal supervisor from the beginning of the project. Jacqui Glass was the second supervisor at Loughborough University at the time the experiments for this paper were conducted and the paper was written. Dino Bouchlaghem and Chimay Anumba were supervisors during their time at Loughborough University, and remained active contributors after moving to other organisations.

\section{Conflicts of Interest}

The authors declare there are no conflicts of interest.

\section{References}

1. Baker, W.F. S.O.M. Structural Engineering Partner. In Proceedings of the World's Tallest Building, Burj Dubai, UAE, Seoul, Korea, 10-14 October 2004. 
2. Skelton, I.; Demian, P.; Bouchlaghem, D. Britain's tall building boom: Now bust? Proc. Inst. Civ. Eng. Struct. Build. 2009, 162, 161-168.

3. Skelton, I.; Demian, P.; Bouchlaghem, D.; Anumba, C. The State-of-the-art of Building Tall. Challenges, Opportunities and Solutions in Structural Engineering and Construction; Taylor \& Francis Group: London, UK, 2010.

4. Shapria, M.; Lucko, G.; Schexnayder, C. Cranes for Building Construction Projects. J. Constr. Eng. Manag. 2007, 133, 690-700.

5. Morby, A. Dreaming Spires for the Towering Giants. Available online: http://www.cnplus. co.uk/news/dreaming-spires-for-the-towering-giants/893729. article (accessed on 23 May 2014).

6. Shiffler, D.A. Crane City. Am. Cranes Transp. 2012, 2, 21-25.

7. Rosenfeld, Y.; Shapira, A. Automation of existing tower cranes: Economic and technological feasibility. Autom. Constr. 1998, 7, 285-298.

8. International Standard ISO 4302-1981. Cranes-Wind Load Assessment. Available online: http://www.iso.org/iso/home/store/catalogue_ics/catalogue_detail_ics.htm?csnumber=10156 (accessed on 16 May 2014).

9. Construction Plant Hire Association (CPA). Tower Crane Interests Group and Health \& Safety Executive the Tower Crane Operator's Handbook; Health and Safety Executive (HSE): London, UK, 2008; pp. 27-28.

10. Ross, B.; McDonald, B.; Vijay Saraf, S.E. Big Blue Goes Down. The Miller Park Crane Accident. Eng. Fail. Anal. 2006, 14, 942-961.

11. OSHA. 1999. Big Blue Crane. Video by Occupational Safety \& Health Administration safety inspector on site the day of the collapse. Available online: http://www.osha.gov/video/bigblue.wmv (accessed on 25 November 2013).

12. Riewestahl, B. Lampson Transi-Lift "Big Blue” Crane Collapse E.I.T., M.S., Penn State, 2010. Available online: https://www.youtube.com/watch? $\mathrm{v}=\mathrm{zRvQ1EbJnqc} \mathrm{(accessed} \mathrm{on} 23$ May 2014).

13. Anderson, J. Fundamentals of Aerodynamics; McGraw-Hill: New York, NY, USA, 2010; pp. 23-24.

14. Kermode, A.; Philpot, D.R.; Barnard, R.H. Mechanics of Flight; Prentice Hall: London, UK, 2012.

15. Dole, C.E.; Lewis, J.E. Flight Theory and Aerodynamics: A Practical Guide for Operational Safety; John Wiley \& Sons: New York, NY, USA, 2000; p. 351.

16. Allen, J.E.E. Aerodynamics. The Science of Air in Motion; University of Michigan: Michigan City, MI, USA, 1999; pp. 83-85.

17. Drela, M. XFOIL: An Analysis and Design System for Low Reynolds Number Airfoils; Springer: Berlin, Heidelberg, Germany, 1989.

18. Barlow, J.B.; Rae, W.H.; Pope, A. Low Speed Wind Tunnel Testing; Wiley-Interscience: Ann Arbor, MI, USA, 1999; pp. 143-149.

(C) 2014 by the authors; licensee MDPI, Basel, Switzerland. This article is an open access article distributed under the terms and conditions of the Creative Commons Attribution license (http://creativecommons.org/licenses/by/3.0/). 